\title{
Abdominal Fat Aspiration Biopsy and Genotyping of Serum Amyloid A Contribute to Early Diagnosis of Reactive AA Amyloidosis Secondary to Rheumatoid Arthritis
}

\author{
Wataru IsHII, Masayuki MATSUdA, Akinori NAKAMURA, Naoshi NAKAMURA*, \\ Akio SUZUKI** and Shu-ichi IKEDA
}

\begin{abstract}
Objective To detect amyloid deposits in the early phase of illness, we investigated the usefulness of abdominal fat aspiration biopsy along with genotyping of serum amyloid A (SAA) in patients with rheumatoid arthritis (RA).

Patients and Methods We performed abdominal fat aspiration biopsy with phenol Congo red staining and determined inflammatory markers, including CRP and $\mathrm{SAA}$, in 217 patients with an RA history longer than 5 years (mean age, 64.1 \pm 10.6 years). Genotypes of SAA1 and 2 were investigated in 127 patients with $\mathrm{RA}$ by a polymerase chain reaction-restriction fragment length polymorphism analysis.

Results In the abdominal fat aspiration biopsy 17 patients $\mathbf{( 7 . 8 \% )}$ ) demonstrated amyloid deposits, which were confirmed as AA type by immunostaining on biopsied tissues from other organs, and nine of them showed no clinical symptoms ascribable to amyloidosis. RA patients with amyloidosis showed significantly higher serum levels of CRP $(p<0.05)$ and SAA $(p<0.0001)$ than those without amyloidosis. In the genotyping, amyloid deposition was significantly correlated with the frequency of SAA1.3 $(p<0.005$ vs. $1.1, p<0.05$ vs. 1.5). Comparison of inflammatory markers between the number of SAA1.3 alleles showed that the SAA/CRP ratio and SAA concentration were higher in the 1.3 homozygote than in the others $(\mathbf{p}<\mathbf{0 . 0 5})$. Two patients demonstrated amyloid deposits at the second abdominal fat biopsy one year after the first, and their SAA1 genotypes were 1.3/1.5 and 1.3/1.3.

Conclusion In RA patients confirmed as having SAA1.3, serial examinations with abdominal fat aspira-
\end{abstract}

tion biopsy might contribute greatly to the early detection of amyloidosis during the long-term follow-up. (Internal Medicine 42: 800-805, 2003)

Key words: phenol Congo red, immunostaining, polymerase chain reaction, CRP

\section{Introduction}

Systemic reactive AA amyloidosis develops from association with various inflammatory disorders, including rheumatoid arthritis (RA) (1). In this type of amyloidosis vital organs such as the kidneys and the gastrointestinal (GI) tract are frequently involved from the early phase of illness, leading to irreversible organ dysfunction within several years of diagnosis (1-3). AA-amyloid deposits are formed in tissues by degradation of serum amyloid A (SAA), which is an acute phase reactant, and thus, so constantly high levels of inflammatory reaction are considered to play an important role in the pathogenesis of the disease $(1,4)$. Since there is still no promising therapy for this type of amyloidosis after the appearance of clinical symptoms, it is important to make the diagnosis in the early phase and intensively suppress the production of SAA with anti-inflammatory drugs and/or cytostatics (5).

In the diagnosis of amyloidosis histopathological examinations are always necessary. To start intensive treatment as early as possible before organ dysfunction worsens, therefore, the biopsy techniques employed should be reliable and sensitive enough to detect amyloid deposits in tissues. Recently, we performed both the phenol and the alkaline

From the Third and *the Second Department of Medicine, Shinshu University School of Medicine, Matsumoto and **the Department of Rheumatology, Marunouchi Hospital, Matsumoto

Received for publication January 22, 2003; Accepted for publication April 18, 2003

Reprint requests should be addressed to Dr. Masayuki Matsuda, the Third Department of Medicine, Shinshu University School of Medicine, 3-1-1 Asahi, Matsumoto 390-8621 
Reactive AA Amyloidosis Secondary to RA

Table 1. Results of Abdominal Fat Aspiration Biopsy and Clinical Profiles

\begin{tabular}{|c|c|c|c|c|}
\hline & & \multicolumn{2}{|c|}{ Amyloidosis } & \multirow{2}{*}{ Total } \\
\hline & & Absent & Present & \\
\hline \multicolumn{2}{|c|}{ Number of patients } & 200 & 17 & 217 \\
\hline \multicolumn{2}{|l|}{ Age (years) } & $62.8 \pm 10.7$ & $72.4 \pm 3.4 * *$ & $64.1 \pm 10.6$ \\
\hline \multicolumn{2}{|c|}{ Disease duration (years) } & $15.5 \pm 9.5$ & $22.0 \pm 11.3$ & $16.4 \pm 9.9$ \\
\hline \multirow[t]{3}{*}{ Laboratory data } & CRP (mg/dl) & $2.91 \pm 2.82$ & $5.39 \pm 4.07 * * *$ & $3.25 \pm 3.12$ \\
\hline & $\mathrm{ESR}(\mathrm{mm} / \mathrm{h})$ & $56.6 \pm 31.0$ & $72.2 \pm 35.8$ & $58.8 \pm 32.0$ \\
\hline & $\mathrm{SAA}(\mu \mathrm{g} / \mathrm{ml})$ & $75.4 \pm 97.0$ & $573.4 \pm 306.4^{*}$ & $141.3 \pm 220.6$ \\
\hline
\end{tabular}

ESR: erythrocyte sedimentation rate, SAA: serum amyloid A. ${ }^{*} \mathrm{p}<0.0001, * * \mathrm{p}<0.001, * * * \mathrm{p}<0.05$.

Congo red stainings in abdominal fat tissues biopsied from 10 patients with RA-related AA amyloidosis, and demonstrated that the former was superior to the latter with respect to sensitivity and reliability for detecting amyloid (6). To confirm the usefulness of abdominal fat aspiration biopsy with phenol Congo red staining in the early diagnosis of AA amyloidosis, we performed this biopsy in patients with a history of RA of more than 5 years as a routine procedure, and simultaneously investigated the relationship between SAA gene polymorphism and amyloidogenesis.

\section{Materials and Methods}

\section{Patients}

We performed abdominal fat aspiration biopsy in 217 Japanese patients with RA (27 men and 190 women; age range, 39 to 89 years; mean, $64.1 \pm 10.6$ years) to look for the presence of amyloid deposits (Table 1). The diagnosis of RA was defined by the revised criteria of the American Rheumatism Association (7), and all of the patients had a history of RA of more than 5 years (history range, 5 to 40 years; mean, $16.4 \pm 9.9$ years). The global functional status of RA was evaluated in each patient according to the revised criteria of the American College of Rheumatology (8). In all patients, CRP, erythrocyte sedimentation rate (ESR) and SAA were determined within one month before each abdominal fat aspiration biopsy.

\section{Abdominal fat aspiration biopsy and phenol Congo red staining}

Skin and subcutaneous tissue around the umbilicus of the patients were anesthetized with $1 \%$ lidocaine. The fat was aspirated with an 18-gauge needle connected to a $20 \mathrm{ml}$ syringe. At least two visible fragments of fat were placed on a glass slide and crushed into a single layer by pressing a second slide against the first. After the smears were dried in air at $50^{\circ} \mathrm{C}$ for at least 30 minutes and fixed with $20 \%$ formalin neutral buffer solution (Wako Pure Chemical, Osaka, Japan) for 5 minutes, these specimens were processed for the phenol Congo red staining.

Phenol Congo red staining has been described elsewhere
$(6,9)$. Briefly, Congo red dye dissolved in distilled water was mixed with $\mathrm{NaCl}$ and subsequently with an equal volume of $100 \%$ ethanol. After saturation at $4^{\circ} \mathrm{C}$, the supernatant of this mixture was used as the basic dye solution. Just before staining, phenol (Nacalai Tasque, Kyoto, Japan) was added at $5 \mathrm{~g} / 100 \mathrm{ml}$ of the basic dye solution, and the $\mathrm{pH}$ was adjusted to around 3.0 by adding $100 \%$ acetate. The glass slides holding aspirated abdominal fat were put into this solution for 1 hour. Hematoxylin-Meyer dye was employed for nuclear staining, and specimens were just briefly put into $100 \%$ ethanol for dehydration. The materials were examined under a polarizing microscope (Nikon, Eclipse, E600POL) and the presence of amyloid was confirmed by its characteristic apple-green birefringence. In patients positive for the phenol Congo red staining other biopsied tissues, including gastroduodenal mucosa and kidneys, were immunohistochemically examined using antibodies to several amyloid precursor proteins including an anti-AA antibody (DAKO, Kyoto, Japan), to make a final diagnosis of AA amyloidosis.

\section{Determination of SAA allele}

To investigate SAA alleles, blood samples were obtained from RA patients who had undergone abdominal fat aspiration biopsy, with their informed consent. Genomic DNA was prepared from the buffy coats using a DNA isolation kit (QIAamp Blood Kit, Funakoshi, Tokyo, Japan). According to the method of Yamada et al with several modifications $(10,11)$, genotypes of SAA1 and 2 were determined using the genomic DNA of the patients by a polymerase chain reaction-restriction fragment length polymorphism analysis (PCR-RFLP). Specific portions of DNA were amplified using the primer sets: $5^{\prime}$-ATGATGCTGCCAAAAGGGGA3' (upstream) and 5'-TGGCCAAAGAATCTCTGGAT-3' (downstream) for SAA1, and 5'-TGCCTGCCTGCACTAC AGCAATGC-3' (upstream) and 5'-TCCCTGCCCCGAGG GCCTCATTGC-3' (downstream) for SAA2. PCR was carried out for 35 cycles at $94^{\circ} \mathrm{C}$ for 1 minute, $60^{\circ} \mathrm{C}$ for 1 minute and $72^{\circ} \mathrm{C}$ for 1 minute. To determine SAA1 genotype the PCR products were digested by Ban I and Bcl I (New England BioLab, Beverly, MA) at $37^{\circ} \mathrm{C}$ for 1 hour and 
subsequently at $50^{\circ} \mathrm{C}$ for 1 hour, and subjected to $3 \%$ agarose gel electrophoresis. In SAA2 genotyping Nco I (New England BioLab, Beverly) was employed as a digestive enzyme at $37^{\circ} \mathrm{C}$ for 3 hours. The DNA was visualized using ethidium bromide under ultraviolet light.

\section{Data analysis}

Data were analyzed using the Mann-Whitney U test, the $\chi^{2}$ test and the multiple logistic regression test. Commercially available statistics software was used for data analysis (StatView for Macintosh, Abacus Concepts, Berkeley, CA).

\section{Results}

\section{Abdominal fat aspiration biopsy}

Abdominal fat aspiration biopsy was safely performed with no complications during or after the procedure in all patients, and repeated several times at intervals of six months to one year randomly in 35 patients with negative results at the first examination. Amyloid deposition was detected in 17 patients (7.8\%), and was confirmed as AA type based on immunohistological studies in other biopsied tissues, mainly from gastroduodenal mucosa (Table 1). Two patients showed negative results at the first biopsy, but apparent amyloid deposits were detected at the second examination after an interval of one year. In RA patients with AA amyloidosis the mean age and disease duration were $72.4 \pm 3.4$ and $22.0 \pm 11.3$ years, respectively. The RA patients with amyloidosis were significantly older than those without (62.8 \pm 10.7 years) $(\mathrm{p}<0.001)$, but there was no significant difference in disease duration (15.5 \pm 9.5 years). In laboratory data CRP and SAA showed significantly higher levels in RA patients with amyloidosis than in those without $(\mathrm{p}<0.05$ and $\mathrm{p}<0.0001$, respectively), while no significant differences were seen in ESR between patients with and without amyloidosis.

\section{Genotyping of SAA}

SAA genotyping was performed in 127 (24 men and 103 women; mean age, 63.4 \pm 11.1 years; mean disease duration,
Table 2. Frequency of SAA Alleles and Amyloid Deposition

\begin{tabular}{|c|c|c|c|}
\hline \multirow{2}{*}{ SAA allele } & \multicolumn{2}{|c|}{ Amyloidosis } & \multirow{2}{*}{$\chi^{2}$} \\
\hline & Absent & Present & \\
\hline 1.1 & 98 & 9 & \multirow{3}{*}{$10.83 *$} \\
\hline 1.3 & 61 & 19 & \\
\hline 1.5 & 61 & 6 & \\
\hline 2.1 & 167 & 24 & \multirow{2}{*}{$0.45(\mathrm{NS})$} \\
\hline 2.2 & 53 & 10 & \\
\hline
\end{tabular}

*p<0.005, SAA: serum amyloid A, NS: not significant.

$15.8 \pm 9.5$ years) of the $217 \mathrm{RA}$ patients involved in this study. The relationship between frequency of SAA alleles and amyloidogenesis is summarized in Table 2. In SAA1 amyloidogenesis was significantly correlated with the allele 1.3 ( $\mathrm{p}<0.005$ vs. the allele $1.1, \mathrm{p}<0.05$ vs. the allele 1.5), while no significant relationship was found between any SAA2 genotype and amyloidosis. Clinical profiles of RA patients classified by SAA1 genotype are summarized in Table 3. In SAA1 the most common genotype was $1.1 / 1.1$ and the second was 1.1/1.5, but amyloid deposition was most frequently seen in $1.3 / 1.3$. There were statistically no significant differences in the age, the global functional status and disease duration between genotypes. When the blood was obtained from RA patients almost all of them were taking various medications (low-dose corticosteroid 62.1\%, disease modifying anti-rheumatic drugs (DMARDs) $57.5 \%$, and immunosuppressive agents $13.8 \%$ ) against RA, and a combination therapy with corticosteroid and DMARDs was most common among them. Nine patients received no medication other than non-steroidal anti-inflammatory drugs because of either mild arthritis or burned-out state of joints with severe deformity.

To assess the influence of the SAA1.3 allele on the production of inflammatory markers, we examined the relationship between the number of SAA1.3 alleles and either SAA and CRP concentrations or SAA/CRP ratios (Table 4).

Table 3. Clinical Profiles of RA Patients Classified by SAA Genotype

\begin{tabular}{|c|c|c|c|c|c|c|c|c|}
\hline \multirow{2}{*}{$\begin{array}{l}\text { SAA1 } \\
\text { genotype }\end{array}$} & \multirow{2}{*}{$\begin{array}{c}\text { No. } \\
\text { (male) }\end{array}$} & \multirow{2}{*}{ Age* } & \multicolumn{4}{|c|}{ Class** } & \multirow{2}{*}{$\begin{array}{l}\text { Disease duration* } \\
\text { (years) }\end{array}$} & \multirow{2}{*}{ Amyloidosis } \\
\hline & & & I & II & III & IV & & \\
\hline $1.1 / 1.3$ & $18(2)$ & 62.7 & 2 & 9 & 5 & 2 & 14.7 & 0 \\
\hline $1.1 / 1.5$ & $27(9)$ & 64.6 & 4 & 5 & 10 & 8 & 14.3 & 3 \\
\hline $1.3 / 1.3$ & $18(1)$ & 63.2 & 0 & 7 & 8 & 3 & 16.6 & 8 \\
\hline $1.5 / 1.5$ & $7(0)$ & 57.8 & 1 & 3 & 3 & 0 & 14.9 & 0 \\
\hline Total & $127(24)$ & 63.4 & 19 & 47 & 40 & 21 & 15.8 & 17 \\
\hline
\end{tabular}

*Age and disease duration are mean values. ${ }^{*}$ Global functional status classified according to the revised criteria of the American Rheumatism Association in 1991. SAA: serum amyloid A, RA: rheumatoid arthritis. 
Table 4. Comparison of Mean Concentrations of SAA and CRP with the Number of SAA1.3 Alleles

\begin{tabular}{lccc}
\hline & \multicolumn{3}{c}{ No.of SAA1.3 alleles } \\
\cline { 2 - 4 } & 0 & 1 & 2 \\
\hline SAA $(\mu \mathrm{g} / \mathrm{ml})$ & $109.0 \pm 150.2$ & $98.1 \pm 164.2$ & $336.1 \pm 377.3^{*}, * *$ \\
CRP $(\mathrm{mg} / \mathrm{dl})$ & $3.65 \pm 3.81$ & $3.97 \pm 4.67$ & $3.75 \pm 4.22$ \\
SAA/CRP & $65.5 \pm 117.6$ & $109.4 \pm 296.3$ & $88.4 \pm 84.5^{*} * *$ \\
\hline
\end{tabular}

${ }^{*} \mathrm{p}<0.05$ vs. group without SAA1.3. ${ }^{*} \mathrm{p}<0.05$ vs. group with one allele of SAA1.3. SAA: serum amyloid A.

SAA1.3 had no significant influence on the CRP concentrations, whereas SAA concentrations and SAA/CRP ratios correlated well with the number of SAA1.3 alleles. In particular, homozygotes of 1.3 showed significantly higher levels in both SAA concentrations and SAA/CRP ratios than other genotypes with or without $1.3(\mathrm{p}<0.05)$.

The clinical profiles of patients with systemic reactive AA amyloidosis secondary to RA are summarized in Table 5 .
The 17 patients consisted of 16 women and 1 man, and all of them are considered to belong to the advanced stage of RA in terms of global functional status except for cases 1 and 8 . In cases 3 and 17 amyloid deposits were detected at the second biopsy performed one year after the first, and their SAA1 genotypes were $1.3 / 1.5$ and $1.3 / 1.3$, respectively. Amyloid deposits were confirmed as AA type in specimens biopsied from other organs, including gastroduodenal mucosa in all patients and renal tissues in case 15 . Nine patients showed no symptoms ascribable to amyloidosis, while the other 8 patients manifested renal dysfunction or gastrointestinal symptoms, including alternating constipation and diarrhea, and intestinal pseudo-obstruction. In case 12, intestinal pseudo-obstruction and spontaneous pneumoperitoneum possibly due to amyloidosis developed suddenly, but these symptoms improved with conservative therapy alone. None of the patients showed either liver dysfunction or electrocardiogram abnormalities, including conduction block, low voltage and QS pattern in precordial leads. During our follow-up of the patients, cases 10 and 14 died from renal failure 2 years 9 months and 1 year 6 months after

Table 5. Clinical Profiles of the Patients with Systemic Reactive AA Amyloidosis Secondary to Rheumatoid Arthritis

\begin{tabular}{|c|c|c|c|c|c|c|c|}
\hline Case & Sex/Age & $\begin{array}{l}\text { Duration of } \\
\text { illness } \\
\text { (years) }\end{array}$ & Class $^{1}$ & SAA1 & $\begin{array}{c}\text { Renal } \\
\text { dysfunction }\end{array}$ & $\begin{array}{l}\text { Gastrointestinal } \\
\text { symptoms }\end{array}$ & $\begin{array}{l}\text { Follow-up period } \\
\text { from diagnosis of } \\
\text { amyloidosis }\end{array}$ \\
\hline 1 & F/64 & 7 & II & $1.3 / 1.3$ & $(-)$ & $(-)$ & $\begin{array}{l}1 \text { year } \\
6 \text { months }\end{array}$ \\
\hline 2 & $\mathrm{~F} / 78$ & 6 & III & $1.3 / 1.5$ & $(-)$ & $(-)$ & $\begin{array}{l}1 \text { year } \\
3 \text { months }\end{array}$ \\
\hline $3^{*}$ & $\mathrm{~F} / 70$ & 32 & III & $1.3 / 1.5$ & $(-)$ & $(-)$ & 1 year \\
\hline 4 & $\mathrm{~F} / 70$ & 27 & III & $1.1 / 1.1$ & $(-)$ & $(-)$ & 1 year \\
\hline 5 & $\mathrm{~F} / 76$ & 39 & III & $1.3 / 1.3$ & $(-)$ & $(-)$ & $\begin{array}{l}1 \text { year } \\
2 \text { months }\end{array}$ \\
\hline 6 & $\mathrm{~F} / 75$ & 18 & III & $1.1 / 1.1$ & $(-)$ & $(-)$ & $\begin{array}{l}1 \text { year } \\
1 \text { month }\end{array}$ \\
\hline 7 & $F / 76$ & 36 & IV & $1.3 / 1.3$ & $(-)$ & $(-)$ & 8 months \\
\hline 8 & $\mathrm{~F} / 51$ & 13 & II & $1.1 / 1.5$ & $(-)$ & $(-)$ & 5 months \\
\hline 9 & $\mathrm{~F} / 52$ & 17 & IV & $1.1 / 1.5$ & $(-)$ & $(-)$ & 6 months \\
\hline 10 & $\mathrm{~F} / 70$ & 26 & IV & $1.3 / 1.3$ & $(+)$ & $(-)$ & $\begin{array}{l}2 \text { years } \\
9 \text { months }\end{array}$ \\
\hline 11 & $\mathrm{~F} / 73$ & 24 & IV & $1.1 / 1.1$ & $(-)$ & $(+)^{2}$ & $\begin{array}{l}1 \text { year } \\
6 \text { months }\end{array}$ \\
\hline 12 & $\mathrm{M} / 70$ & 11 & III & $1.3 / 1.3$ & $(+)$ & $(+)^{3}$ & 8 months \\
\hline 13 & $\mathrm{~F} / 73$ & 15 & IV & $1.1 / 1.5$ & $(+)$ & $(+)^{2}$ & 6 months \\
\hline 14 & $\mathrm{~F} / 70$ & 16 & IV & $1.3 / 1.3$ & $(+)$ & $(-)$ & $\begin{array}{l}1 \text { year } \\
6 \text { months }\end{array}$ \\
\hline 15 & $\mathrm{~F} / 58$ & 12 & III & $1.3 / 1.5$ & $(+)$ & $(-)$ & $\begin{array}{l}3 \text { years } \\
8 \text { months }\end{array}$ \\
\hline 16 & $\mathrm{~F} / 53$ & 11 & III & $1.3 / 1.3$ & $(+)$ & $(-)$ & $\begin{array}{l}1 \text { year } \\
5 \text { months }\end{array}$ \\
\hline $17^{*}$ & $\mathrm{~F} / 54$ & 15 & III & $1.3 / 1.3$ & $(+)$ & $(+)^{2}$ & 4 months \\
\hline
\end{tabular}

${ }^{1}$ The global functional status of rheumatoid arthritis classified according to the criteria of the American College of Rheumatology in 1991. ${ }^{2}$ Alternating constipation and diarrhea. ${ }^{3}$ Intestinal pseudo-obstruction. ${ }^{4}$ Period from diagnosis of AA amyloidosis to death. Both patients died of renal failure. *These patients were diagnosed as having amyloidosis at the second biopsy of abdominal fat tissues. 
the diagnosis of amyloidosis, respectively, but the other cases are still alive.

\section{Analysis of multiple factors contributing to amyloido- genesis}

A multiple logistic regression test was employed to assess the influence of multiple factors, including the age of the patients, CRP and SAA concentrations in serum, and the number of SAA1.3 alleles, on amyloidogenesis. CRP and SAA concentrations were significantly correlated with the presence of AA amyloid $(\mathrm{p}<0.05$ and $\mathrm{p}<0.0001$, respectively), while no significant relationship was found between amyloidosis and either the number of SAA1.3 alleles or the age of the patients.

\section{Discussion}

In the histopathological diagnosis of reactive AA amyloidosis either the gastroduodenal and rectal mucosa or abdominal fat tissue has been commonly used as a biopsy site $(1,12-18)$. A few reports have shown that the bulbus and the second portion of the duodenum are the most sensitive site for biopsy $(15,16)$, but an endoscopic examination is often difficult and risky in RA patients, particularly in those with either various complications, including ischemic heart disease, or involvement of the cervical spine. With respect to procedural ease and safety, the abdominal fat is superior to the gastrointestinal tract. Abdominal fat aspiration biopsy nevertheless has several disadvantages. Materials prepared from the aspirated abdominal fat tissues are not usable for immunohistochemical staining, so other biopsied tissues are necessary to determine the immunohistochemical typing of amyloid protein. Another disadvantage is the low sensitivity for detecting AA-amyloid deposits. Recently, however, we demonstrated that the sensitivity of abdominal fat aspiration biopsy could be enhanced by employing phenol Congo red as a staining method instead of the conventional alkaline Congo red (6). This biopsy technique was therefore used in our study in combination with phenol Congo red staining, and showed associated AA amyloidosis in $7.8 \%$ of patients; half of these lacked any symptoms ascribable to AA amyloidosis. This rate is almost the same as that shown in the previous biopsy studies $(1,15,16)$. These results suggest that abdominal fat aspiration biopsy with phenol Congo red staining is sufficiently sensitive and useful in the diagnosis of systemic reactive AA amyloidosis secondary to RA even before the appearance of clinical symptoms.

The precise pathogenetic mechanism of systemic reactive AA amyloidosis remains unclear, but two factors are considered to be mainly responsible from the viewpoint of hostdisease relationship: one is the status of inflammatory disorders and the other is genetic background. Because SAA fluctuates in parallel with the activity of inflammatory disorders, poorly controlled RA frequently causes high levels of SAA for a long period of time and leads to amyloid formation. Also in our study the patients with AA amyloidosis showed significantly high levels of inflammatory reactions, including SAA and CRP, and there was a significant correlation between these values and amyloidosis in multiple factor analysis. In poorly controlled RA patients with high serum levels of inflammatory markers, therefore, repeated biopsy from abdominal fat tissues is necessary to detect associated amyloidosis in the early phase.

In general the disease duration from the onset of RA to the diagnosis of AA amyloidosis is longer than 15 years (2), and its mean value was around 22 years in our study. This type of amyloidosis, however, sometimes develops relatively earlier than usual in the long-term follow-up of RA patients despite low inflammatory reactions. In these instances some genetic factors might be closely related to the amyloidogenesis. Polymorphism of apolipoprotein $\mathrm{E}$ has been investigated as a potentially relevant genetic background because this substance is generally involved in the process of amyloid deposition $(19,20)$. According to several recent reports apolipoprotein E4 was positively related to the development of AA amyloidosis in patients with RA $(21,22)$. As another factor contributing to the development of AA amyloidosis, much attention has been paid to SAA polymorphism (2326). SAA is a polymorphic protein, for which there are at least four major loci present (SAA1-4) in humans (4). Because SAA3 is a pseudogene with no product and SAA4 does not change in serum concentration during an acute phase response, amyloid fibrils are considered to be formed in tissues from both SAA1 and 2, but predominantly from SAA1 in humans (27). Synthesis of amyloid protein from SAA1 and 2 is strongly induced by inflammatory cytokines such as interleukin-6 in the liver as an acute phase reactant in parallel with the disease activity of RA (4). Allelic polymorphism consists of 1.1-1.5 in SAA1 and 2.1-2.2 in SAA2 (28), and several recent reports have shown that the development of AA amyloidosis in RA is positively related to the frequency of either 1.3 in the Japanese population or 1.1 in Caucasians (23-25). Also in our study around two-thirds of the patients with AA amyloidosis have 1.3 in SAA1 genotyping, and a statistically significant relationship could be found between the association of reactive AA amyloidosis and SAA1.3. Two patients demonstrated amyloid deposits at the second abdominal fat aspiration biopsy performed after an interval of one year, and both of them had SAA1.3 in the genotyping. These results suggest that serial studies using abdominal fat aspiration biopsy contribute to early diagnosis of AA amyloidosis in RA patients, particularly in those confirmed as having SAA 1.3. In the long-term follow-up of patients with chronic inflammatory disorders, including RA, therefore, a combination of SAA genotyping and serial abdominal fat aspiration biopsies might be useful and reliable as routine procedures to detect the presence of AA amyloidosis in the early phase and to start intensive treatment, although a prospective study is of course necessary to confirm this speculation.

There are two possibilities concerning the mechanism of how the SAA1.3 allele influences amyloidogenesis: one is 


\section{Reactive AA Amyloidosis Secondary to RA}

increased production of SAA and the other is its structural change. To assess the production of SAA irrespective of inflammatory activity we determined the SAA/CRP ratio, because SAA concentrations easily fluctuate as an acute phase reactant in parallel with CRP. In our study both SAA concentrations and SAA/CRP ratios correlated well with the number of SAA1.3 alleles, and showed significantly higher values in homozygotes of SAA1.3 than in other genotypes. These results support the cencept that the SAA1.3 allele positively influences the production of SAA, leading to amyloidogenesis. According to a recent report, however, homozygotes of SAA1.5 showed higher SAA/CRP ratios than other genotypes and the SAA1.3 allele was related to neither SAA/CRP ratios nor SAA concentrations (29). This controversial finding is probably ascribable to the selection of subjects and the disease phase when blood was taken. To clarify the relationship between SAA1.3 and amyloidogenesis further investigations are necessary.

Acknowledgement: This work was supported by a grant from the Intractable Disease Division, the Ministry of Health and Welfare, Amyloidosis Research Committee, Japan.

\section{References}

1) Buxbaum J. The amyloidoses. in: Rheumatology. 2nd ed. Klippel JH, Dieppe PA, Eds. Mosby, London, 1998: 8.27.1-10.

2) Gertz MA, Kyle RA. Secondary systemic amyloidosis. Response and survival in 64 patients. Medicine 70: 246-256, 1991.

3) Joss N, McLaughlin K, Simpson K, Boulton-Jones JM. Presentation, survival and prognostic markers in AA amyloidosis. Q J Med 93: 535$542,2000$.

4) Husby G, Marhaug G, Dowton B, Sletten K, Sipe JD. Serum amyloid A (SAA): Biochemistry, genetics and the pathogenesis of AA amyloidosis. Amyloid: Int J Exp Clin Invest 1: 119-137, 1994.

5) Gillmore JD, Lovat LB, Persey MR, Pepys MB, Hawkins PN. Amyloid load and clinical outcome in AA amyloidosis in relation to circulating concentration of serum amyloid A protein. Lancet 358: 24-29, 2001.

6) Ishii W, Matsuda M, Nakamura N, et al. Phenol Congo red staining enhances the diagnostic value of abdominal fat aspiration biopsy in reactive AA amyloidosis secondary to rheumatoid arthritis. Intern Med $\mathbf{4 2}$ 400-405, 2003.

7) Arnett FC, Edworthy SM, Bloch DA, et al. The American Rheumatism Association 1987 revised criteria for the classification of rheumatoid arthritis. Arthritis Rheum 31: 315-324, 1988.

8) Hochberg MC, Chang RW, Dwosh I, Lindsey S, Pincus T, Wolfe F. The American College of Rheumatology 1991 revised criteia for the classification of global functional status in rheumatoid arthritis. Arthritis Rheum 35: 498-502, 1992.

9) Sai S, Hayama M, Hotchi M. A new amyloid stain by phenol Congo red. Byouri to Rinshou (Pathology and Clinical Medicine) 4: 12291232, 1986 (in Japanese).

10) Yamada T, Okuda $Y$, Itoh $Y$. The frequency of serum amyloid A2 alleles in the Japanese population. Amyloid: Int J Exp Clin Invest 5: 208-211, 1998.

11) Yamada $T$, Wada $A$, Itoh $Y$, Itoh $K$. Serum amyloid $A 1$ alleles and plasma concentrations of serum amyloid A. Amyloid: Int J Exp Clin
Invest 6: 199-204, 1999.

12) Libbey CA, Skinner M, Cohen AS. Use of abdominal fat tissue aspirate in the diagnosis of systemic amyloidosis. Arch Intern Med 143: 1549$1552,1983$.

13) Klemi PJ, Sorsa S, Happonen RP. Fine-needle aspiration biopsy from subcutaneous fat. An easy way to diagnose secondary amyloidosis. Scand J Rheumatol 16: 429-431, 1987.

14) Friedman S, Janowitz HD. Systemic amyloidosis and the gastrointestinal tract. Gastroenterol Clin North Am 27: 595-614, 1998.

15) Kobayashi $\mathrm{H}$, Tada $\mathrm{S}$, Fuchigami $\mathrm{T}$, et al. Secondary amyloidosis in patients with rheumatoid arthritis: Diagnostic and prognostic value of gastroduodenal biopsy. Br J Rheumatol 35: 44-49, 1996.

16) Okuda $Y$, Takasugi K. Diagnostic and prognostic study of secondary amyloidosis complicating rheumatoid arthritis. Amyloid and Amyloidosis. Parthenon Publishing Group, New York, 1998: 426-428.

17) Hazenberg BPC, Limburg PC, Bijzet J, van Rijswijk MH. A quantitative method for detecting deposits of amyloid A protein in aspirated fat tissue of patients with arthritis. Ann Rheum Dis 58: 96-102, 1999.

18) Gomez-Casanovas E, Sanmarti R, Sole M, Canete JD, Munoz-Gomez $\mathrm{J}$. The clinical significance of amyloid fat deposits in rheumatoid arthritis. A systematic long-term followup study using abdominal fat aspiration. Arthritis Rheum 44: 66-72, 2001.

19) Kisilevsky R. The relation of proteoglycans, serum amyloid $P$ and apo E to amyloidosis current status, 2000. Amyloid: Int J Exp Clin Invest 7: 23-25, 2000.

20) Sato C, Castano EM, Prelli F, Kumar RA, Baumann M. Apolipoprotein $\mathrm{E}$ increases the fibrillogenic potential of synthetic peptides derived from Alzheimer's, Gelsolin and AA amyloids. FEBS Lett 371: 110114, 1995.

21) Hasegawa $H$, Nishi $S$, Ito $S$, et al. High prevalence of serum apolipoprotein E4 isoprotein in rheumatoid arthritis patients with amyloidosis. Arthritis Rheum 39: 1728-1732, 1996.

22) Maury CP, Liljestrom M, Tiitinen S, Laiho K, Kaarela K, Ehnholm C. Apolipoprotein $\mathrm{E}$ phenotypes in rheumatoid arthritis with or without amyloidosis. Amyloid: J Protein Folding Disord 8: 270-273, 2001.

23) Booth DR, Booth SE, Gillmore JD, Hawkins PN, Pepys MB. SAA1 alleles as risk factors in reactive systemic AA amyloidosis. Amyloid: Int J Exp Clin Invest 5: 262-265, 1998.

24) Baba S, Masago SA, Takahashi $T$, et al. A novel allelic variant of serum amyloid A, SAA1 $\gamma$ : genomic evidence, evolution, frequency, and implication as a risk factor for reactive systemic AA-amyloidosis. Hum Mol Genet 4: 1083-1087, 1995.

25) Moriguchi M, Terai $C$, Koseki $Y$, et al. Influence of genotypes at SAA1 and SAA2 loci on the development and the length of latent period of secondary AA-amyloidosis in patients with rheumatoid arthritis. Hum Genet 105: 360-366, 1999.

26) Moriguchi $\mathrm{M}$, Terai $\mathrm{C}$, Kaneko $\mathrm{H}$, et al. A novel single-nucleotide polymorphism at the 5'-flanking region of SAA1 associated with risk of type AA amyloidosis secondary to rheumatoid arthritis. Arthritis Rheum 44: 1266-1272, 2001.

27) Liepnieks JJ, Kluve-Beckerman B, Benson MD. Characterization of amyloid A protein in human secondary amyloidosis. The predominant deposition of serum amyloid A1. Biochim Biophys Acta 1270: 81-86, 1995.

28) Revised nomenclature for serum amyloid A (SAA) [editorial]. Amyloid: Int J Exp Clin Invest 6: 67-70, 1999.

29) Yamada T, Okuda Y, Takasugi K, Itoh K, Igari J. Relative serum amyloid A (SAA) values. The influence of SAA1 genotypes and corticosteroid treatment in Japanese patients with rheumatoid arthritis. Ann Rheum Dis 60: 124-127, 2001. 